\title{
Experimental study of flooding area characteristics of flash floods under different bedload transport conditions
}

\author{
Jun $\mathrm{Du}^{1,2, a}$, Chendi Zhang ${ }^{3, b}$ \\ ${ }^{1}$ Changjiang River Scientific Research Institute, Department of Soil and Water Conservation, China \\ ${ }^{2}$ Research center on mountain torrent and geologic disaster prevention, MWR, China \\ ${ }^{3}$ Tsinghua University, Department of Hydraulic Engineering, China \\ ${ }^{a} d x j x 2006 @ 126 . c o m$
}

\begin{abstract}
Keywords: Flash floods; bedload transport; flooding area; river channel morphology; solid model Abstract: Based on the large-scale field conceptual solid model experiments of artificial torrents and water-rock flows, this paper studied the changes of flooding areas and cross-sections morphology of river channel in different bedload transport rates, and the results showed that:1) there is a critical point in bedload transport rate between the bedload transport levels and flooding areas, before the rate reaches the critical point, the more the bedload transport rates, the larger the flooding area; but when the rate reaches the point, the more the bedload transport rates, the smaller the flooding area. 2) The great amount of bedload of flash floods would promote the deposition in river channel and raise the river bed significantly, and this is the reason why flooding area extends with the increase of bedload transport rate in low-level bedload transport of flash floods. However, with the rise of bedload transport rate, the collisions of big particles greatly consumed the flood power, which obviously slows down the flood flow velocity and eventually leads to the reduction of flooding area.
\end{abstract}

\section{Introduction}

The movement of bedload is a kind of basic kinetic feature for flash floods, and it also plays a very important role on the flooding processes. Once the stream carries a large amount of cobble and gravel, the bedload can be deposited easily, which may raise the flood level and cause disasters. However, too many collisions between bedload can also consume a lot of energy and decrease the flow velocity, which may reduce the threat of flooding ${ }^{[1-4]}$. The positive and negative impacts work effectively and simultaneously, making people hard to understand the exact effect of bedload in a disaster process of flash flood. Accordingly, by studying the flooding characteristics under different bedload transport conditions, this paper tries to discuss the problem and summarize the impact rule of different bedload transport rates to flooding processes of flash floods, preliminarily.

\section{Method and Data Processing}

Model scale and similarity criteria. The experiment was based on a conceptual solid model because the intent of this study was not to restore any specific events. In order to achieve a good simulation of the actual disaster environment and improve the applicability of experimental results, the solid model experiments were performed on the alluvial fan of the Jiangjia gully in Yunnan Province, a typical mid-sized debris flow gully with hot and dry climate.

The geometric scale was set to 1:20. According to the Froude similarity criteria, the flow discharge scale was set to be equal to the geometric scale to the power of $1 / 2.5$, and the time and flow velocity scales were set to be equal to the geometric scale to the power of $1 / 0.5$, respectively. The local deposits of debris flows, eliminating the large granular stone, were chosen directly as the experimental material for artificial water-rock flow making. Accordingly, the prototype of this solid model was a small scale flash flood gully with a 40-meter-wide channel and a 160-meter-wide and 300-meter-long alluvial fan, and the scale was common in the mountain area of southwest China. 
Model facilities. The experimental facilities consist of three parts, i.e. a flow control flume, a small pool, and a canal. The Parshall flume was chosen as the flow control flume because of its high precision and low head loss, and it was also the flow outlet of the entire system. The distance between the outlet and the lower flow merging point, i.e. the experimental observing channel length, was about $35 \mathrm{~m}$. The pool, about $15 \mathrm{~m}^{3}$, was connected to the Parshall flume by a sluice gate and drew water from the higher ground through the cement canal. During the experiment, the Parshall flume was found unreliable in discharge recorded for local bad construction technology, thus we reformed the flume and re-calculated the relationship between water level of the flume and discharge (Table 1).

Table 1 Discharge reading of the flow control flume

\begin{tabular}{llll}
\hline $\begin{array}{l}\text { RPF } \\
(\mathbf{m})\end{array}$ & $\begin{array}{l}\text { ED } \\
(\mathbf{L} / \mathbf{s})\end{array}$ & $\begin{array}{l}\mathbf{P D}^{\mathbf{1}} \\
\left(\mathbf{m}^{\mathbf{3}} / \mathbf{s}\right)\end{array}$ & $\mathbf{F S}^{\mathbf{2}}$ \\
\hline 0.27 & 140.55 & 251.43 & Small \\
0.30 & 166.29 & 297.47 & Small \\
0.35 & 212.67 & 380.44 & Middle \\
0.41 & 273.77 & 489.73 & Extreme \\
0.43 & 295.39 & 528.41 & Extreme \\
\hline
\end{tabular}

Notes: 1 means according to Froude similarity criterion; 2 means setting based on recent disaster events; RPF means Reading of Parshall flume; ED means experimental discharge; PD means prototype discharge; FS means flood scale.

Experimental design. The experiment was divided into two stages, i.e. the first stage of artificial torrent and the second stage of artificial water-rock flow. In the first experimental stage, two types of channel layouts, 'channel in the center' and 'channel on one side', were modeled on the artificial fan based on results from previous field investigations. The former refers to the circumstance of the river flowing into the mainstream through the central channel of the alluvial fan, and the latter refers to the circumstance of the river flowing into the mainstream though the channel along one side of the alluvial fan. For both layouts, 8 cross sections with an interval of $2 \mathrm{~m}$ between each other were arranged along the channel of the artificial fan to record the landscape changes before and after each flood event. Besides, the channel of lower gully was also modeled for better monitoring the flooding characteristic inner gully.

The concrete experimental parameters of the two stages are shown in Table 2.

Table 2 Experimental parameters of different artificial floods

\begin{tabular}{lcccc}
\hline No. & Experimental condition & Experimental stage & $\begin{array}{c}\text { Peak discharge } \\
(1 / \mathrm{s})\end{array}$ & $\begin{array}{c}\text { Bedload transport rate } \\
(\mathrm{kg} / \mathrm{s})\end{array}$ \\
\hline 1 & Without deposits & Channel on one side & 272.80 & 2.10 \\
2 & With deposits & Channel on one side & 280.12 & 3.25 \\
3 & Without deposits & Channel on one side & 273.95 & 2.05 \\
4 & With deposits & Channel on one side & 277.23 & 2.70 \\
5 & With deposits & Channel on one side & 286.72 & 3.16 \\
6 & Without deposits & Channel on one side & 274.85 & 1.88 \\
7 & Without deposits & Channel in the center & 285.43 & 2.25 \\
8 & With deposits & Channel in the center & 288.30 & 2.67 \\
9 & With deposits & Channel in the center & 297.82 & 3.13 \\
10 & Without deposits & Channel in the center & 291.86 & 2.23 \\
11 & Without deposits & Channel in the gully & 283.67 & 1.57 \\
12 & With deposits & Channel in the gully & 282.44 & 2.00 \\
13 & With deposits & Channel in the gully & 290.60 & 2.11 \\
14 & Without deposits & Channel in the gully & 283.77 & 1.78 \\
15 & Without deposits & Water flow & 288.52 & 0.96 \\
16 & With deposits & Water-rock flow & 286.88 & 8.12 \\
\hline
\end{tabular}

There were two sets of bedload transport conditions, i.e. with deposits and without deposits, associated with each channel layout, including the 'channel in the gully'. It is found that the bedload deposited easily before they reached monitoring section, thus the upstream deposition area was finally set in the position of $2 \mathrm{~m}$ away from the monitoring section according to the results of repeated tests. The local debris materials, excluding the big stones, were used as experimental deposited materials for scouring. When the experiment started, the materials had to be stacked into 5 natural cones with each volume of $0.1 \mathrm{~m}^{3}$ in the upstream deposition area, so as to make significant difference in bedload transport rate between artificial floods with deposits and without deposits inner monitoring section. 
The second experimental stage was artificial water-rock flow, which was also divided into the two conditions, i.e. with deposits and without deposits conditions. However, instead of previous different layouts of channel, the channels in the model gully and fan were monitored simultaneously in this stage. Besides, in order to simulate the water-rock flow, the upstream deposition area was expanded to $10 \mathrm{~m} \times 1.9 \mathrm{~m}$ so as to stack about $8 \mathrm{~m}^{3}$ materials each scouring test, and the position was transferred directly to the outlet of Parshall flume. The bedload transport rate was controlled by the amount of scouring water.

\section{Effects of bedload on the flooding characteristics}

Theoretically, the great amount of bedload would change the impact and flooding characteristics of flash floods significantly for its complex form of movement and frequent mass exchange with the riverbed. The results of experiment also supported this point.

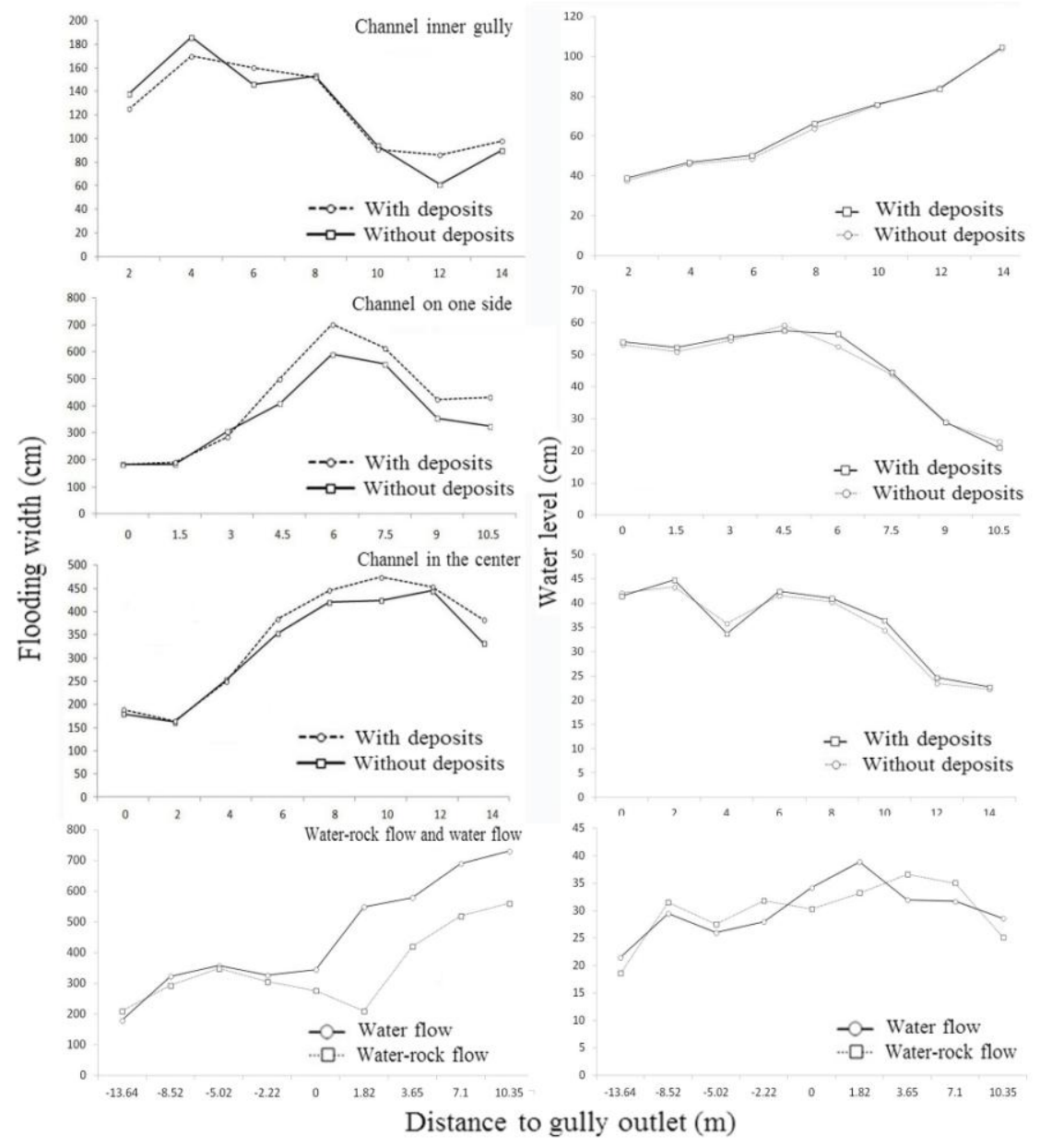

Figure 1 Comparison of flooding area and water level in different experimental conditions

The averages of flooding width of each cross section under different experimental conditions were shown in the Figure 1(left). It can be found that the comparative results from the two experimental stages were different. The flooding areas of torrents with deposits in the first stage were significant larger than that without deposits, especially on the downstream of model fan. However, with the increase of bedload transport rates, the flooding area of water-rock flow in the second stage was smaller than that of water flow. Generally, the changes of water level in the two stages were consistence. No matter in which stage, the water levels of flash floods with deposits were higher than that without deposits (Figure 1 right).

\section{Effects of bedload on the morphology of cross-sections}

Due to the larger mass and volume, the movement of bedload, including the processes of start, transport and deposit, would change the channel morphology obviously, especially in the processes of 
transport and deposit. Generally, with the constant of flow energy, the larger the bedload transport rates of flash floods, the bigger the degrees of change in channel morphology.

The results of experiments also supported the above point. They show that in most conditions the absolute area change of each cross section, i.e. the total area of silting and scouring at each cross section, with deposits were bigger than that without deposits. In the model fan, the increases of the first stage were $5.7 \%$ (channel in the center) and 16.0\% (channel on one side), respectively; the increase of the second stage was $15.6 \%$. In the model gully, the situation was more complex. The absolute area change of each cross section with deposits might be lower than that without deposits. For example, the decreases of the first stage were $9.5 \%$. However, with the increase of the bedload transport rate, the change was again turn to increase in the second stage, and the increase was $5.5 \%$.

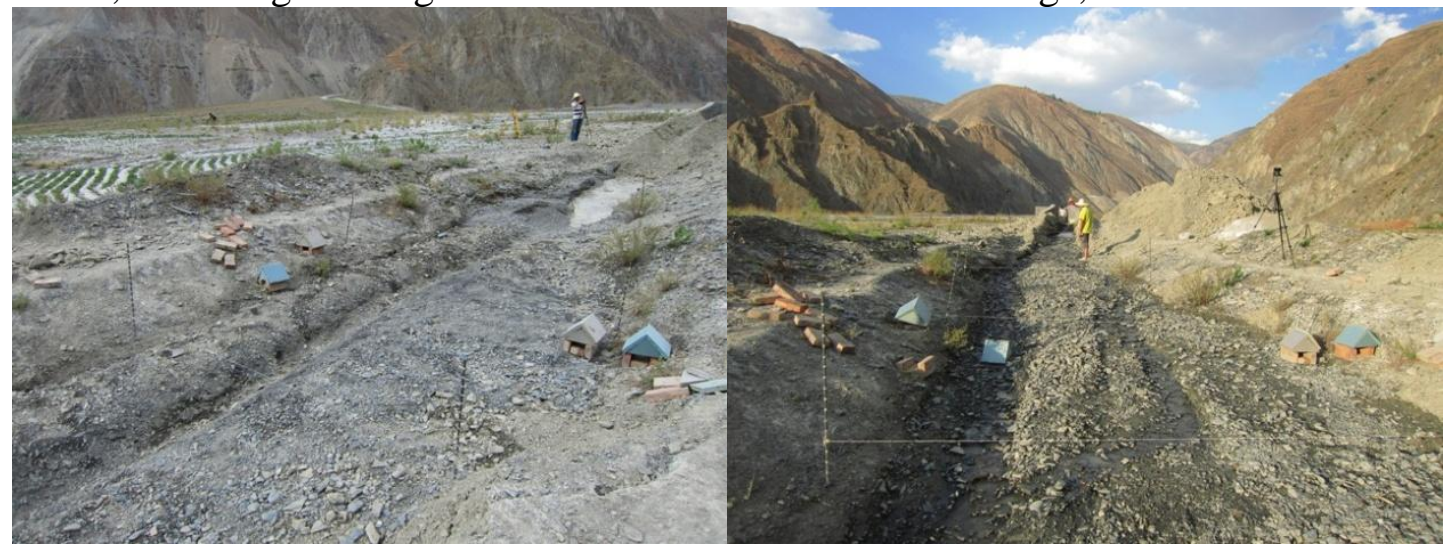

Figure 2 Morphology of channel before (left) and after (right) scouring of the artificial water-rock flow

The effects of deposits on area change of each cross section in different experimental stages were consistence. Generally, the more deposits on the upstream deposition area, the more siltation in the model channel. In the model fan, most cross sections presented siltation. In the model gully, the channel was flat with the river bank after the scouring of water-rock flow because of the serious retrogressive siltation (Figure 2). In some cases of artificial torrents, some cross sections in the gully presented erosion after the scouring of torrents. Nevertheless, the total channel presented siltation.

\section{Impact mechanism of the bedload transport change on flooding area of flash floods}

The experiments indicated that the effect of bedload change on flooding area of flash floods was significant, and the effect was not simply increasing or decreasing the flooding area. Actually, there was a critical rule on this effect. When the bedload transport rates are at a low level, the flooding area expands with the increase of bedload transport rate. However, when the rates exceed a critical point, and the common water flow transfers into water-rock flow naturally, the flooding area reduces with the increase of bedload transport rate (Figure 3).

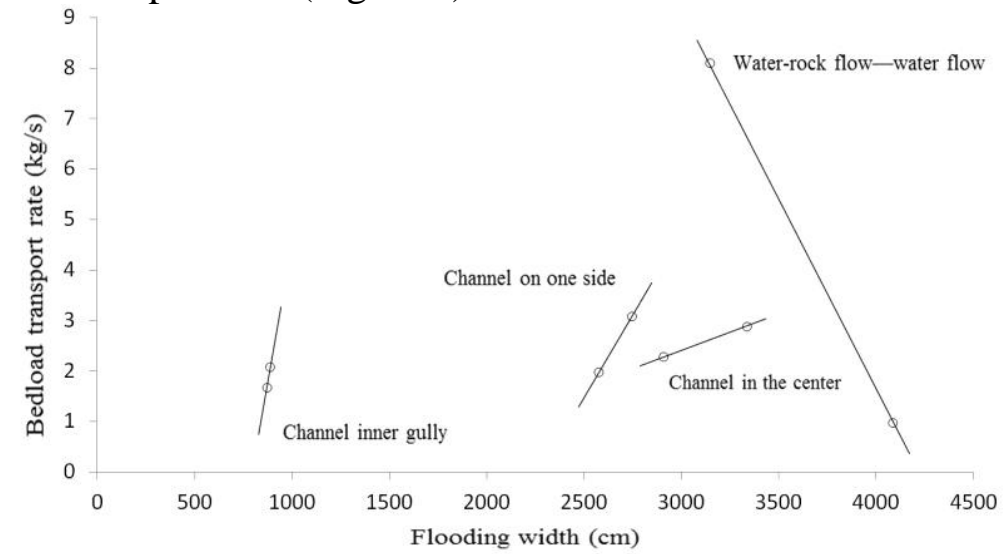

Figure 3 Responses of flooding areas to different bedload conditions 
There are two reasons for this critical phenomenon, one is the effect of bedload increasing on morphological change of channel, and the other is the impact of bedload transport on flow energy. The increase of bedload transport rate could lead to serious siltation and raise the flooding level, which was proved by the experiments repeatedly. On the other hand, the movement of bedload consumes flow power to some extent, thus the increase of bedload could reduce the shock from flash floods effectively, and prevent the further expansion of flooding. In the first experimental stage, the deposits in the deposition area were at a low level, thus the increase of bedload was too small to reduce the flow power largely, and the flooding area was enlarged for the resized flooding level by bedload increasing. However, in the second stage, the bulk density of the water-rock flow was up to $1.58 \mathrm{t} / \mathrm{m}^{3}$, which made the riverbed armoring seriously. The coarse riverbed increased flood resistance, and simultaneously the collisions by the big stones also brought huge energy dissipation. Therefore, the velocity of water-rock flow reduced sharply and the flooding threat was correspondingly decreased. This is consistent with the conclusion from Fei's work ${ }^{[5]}$.

\section{Conclusions}

Based on the results of experiments, it is believed that there was a critical rule between flooding area and bedload transport condition in flash floods. When the bedload transport rates are at a low level, the flooding area expands with the increase of bedload transport rate because of the raising flooding level. However, when the bedload transport rates exceed a critical point, collisions of stones would consume a lot of flow energy, and the armoring riverbed can also increase flood resistance. These two effects on flooding area reduction are far more than that on flooding area expanding, thus the flooding area reduces with the increase of bedload transport rate.

\section{Acknowledgements}

This work was financially supported by The National Natural Science Fund (41501109).

\section{References}

[1] Z.Y. Wang. Experimental study on debris flow head and the energy theory. Journal of Hydraulic Engineering, No.3 (2001), p. 18-26. (in Chinese)

[2] C.B. Liu. Energy equilibrium model of bed-load transport rate. Port and Waterway Engineering, No. 12 (2014), p. 188-190. (in Chinese)

[3] Z.Y. Wang, L.J. Qi and X.Z. Wang. Debris flow control with energy dissipation structures-experiences from Wenjiagou. Journal of Hydraulic Engineering, No. 43 Vol.3 (2012), p. 253-263. (in Chinese)

[4] S.M. Yao and J.Y. Lu. Research on water and sediment transport characteristics downstream the Three Gorges reservoir before and after its impoundment. Journal of Hydroelectric Engineering, No. 30 Vol. 3 (2011), p. 117-123. (in Chinese)

[5] X.J. Fei. Velocity and Transport Concentration of Solid in Water-Stone Debris Flow. Journal of Sediment Research, No. 4 (2002), p. 8-12. (in Chinese) 